\title{
AKSESBILITAS PEJALAN KAKI DI STASIUN YANG TERINTEGRASI DENGAN RENCANA TERHADAP KAWASAN BERKONSEP TOD (STUDI KASUS KAWASAN STASIUN TANJUNG BARAT)
}

\author{
Gading Kencono Aji ${ }^{1}$, Sylvira Ananda ${ }^{2}$, Tri Mulyono ${ }^{3}$ \\ ${ }^{1}$ Pendidikan Teknik Bangunan, FT, UNJ \\ ${ }^{2,3} \mathrm{D} 3$ Transportasi, FT UNJ \\ Email: gading_aji@yahoo.co.id
}

\begin{abstract}
ABSTRAK
Penelitian ini dilakukan untuk menilai jalur pejalan kaki Level Of Service (LOS) di sekitar area Stasiun Tanjung Barat. Selain itu, untuk melihat dari segi kenyamanan dan keamanan dalam menjangkau area berkonsep TOD. Untuk itu diperlukan suatu model desain pedestrian agar pengguna lintasan dapat menikmati jalur pedestrian yang nyaman dan aman. Hasil penelitian ini menunjukkan bahwa tingkat pelayanan pejalan kaki di ruas jalan Tanjung Barat Raya dan di ruas jalan Lenteng Agung raya: Untuk ruas jalan Tanjung Barat indeks LOS dikategorikan " $B$ " sedangkan ruas jalan Lenteng Agung Raya ada di indeks LOS dalam kategori " $C$ ". Dan untuk prediksi 5 tahun ke depan, LOS dikategorikan "B”. Hal ini mengindikasikan perlunya perbaikan dalam hal fasilitas pendukung bagi pejalan kaki di dua St. Western Cape tersebut. Hal ini menunjukkan bahwa fasilitas penunjang pejalan kaki perlu ditingkatkan yang berdampak pada peningkatan jumlah pengguna pejalan kaki di sekitar stasiun Tanjung Barat selama 5 tahun ke depan.
\end{abstract}

Kata kunci: Jalur Pejalan Kaki, Kawasan TOD, Level Of Services (LOS), Stasiun Tanjung Barat

\begin{abstract}
This research was conducted to assess the Level Of Service (LOS) pedestrian path around the Tanjung Barat Station area. In addition, to see in terms of comfort and security in reaching a TOD concept area. For this reason, a model of pedestrian design is needed so that track users can enjoy the pedestrian pathway feeling comfortable and safe. The results of this study indicate that the level of pedestrian service on the Tanjung Barat Raya road and on the road in Lenteng Agung raya: For the Tanjung Barat Raya road the LOS index is categorized as " $B$ " while the Lenteng Agung Raya road is in the LOS index in the " $C$ " category. And for the prediction of the next 5 years, LOS is categorized as " $B$ ". This indicates the need for improvements in terms of supporting facilities for pedestrians on the two St. Western Cape. This indicates that the pedestrian support facilities need to be improved which will have an impact on the increasing number of pedestrian users around the West Tanjung station for the next 5 years.
\end{abstract}

Keywords: Pedestrian Path, TOD area, Level Of Services (LOS), Tanjung Barat Stasion 


\section{PENDAHULUAN}

Kota DKI Jakarta disebut sebagai kota megapolitan. Banyak pendatang daerah berbondong-bodong mencari peruntungan mendatangi Jakarta. Tidak hanya pemukiman warga, pusat pemerintahan, sekolah, gedung perkantoran, dan juga pabrik terdapat di Jakarta. Berdasarkan data di atas, tiap tahun warga Jakarta mengalami peningkatan yang lumayan pesat. Peningkatan ini dikarenakan sulitnya mendapatkan kendaraan umum yang aman, nyaman, dan yang terpenting mudah diakses oleh masyarakat dan tepat waktu serta harganya relatif terjangkau.

Suatu kawasan berkonsep Transit Oriented Development (TOD) merupakan kunci untuk mengurangi tingkat kepadatan kendaaran di jalan. Prinsip TOD ini yang berhubungan dengan konsep transportasi yang berkelanjutan (Tamin, 2008). Pola pembangunan yang memaksimalkan manfaat di sistem angkutan umum, mengembalikan fokus pembangunan kepada penggunanya (manusia), penyediaan aksesbilitas dan moda alternatif bagi siapa saja terutama pejalan kaki, mendorong pertumbuhan ekonomi kota, serta ramah lingkungan merupakan prinsip dasar tranportasi yang berkelanjutan (ITDP, 2017: 6). Suatu kawasan pemukiman yang memiliki beragam fasilitas penunjang untuk kebutuhan masyarakat, misalnya seperti: sekolah, rumah sakit, pusat perbelanjaan, dan fasilitas penunjang lainnya.

\section{Apa yang membuat Anda memilih berjalan kaki di kawasan ini? ...}

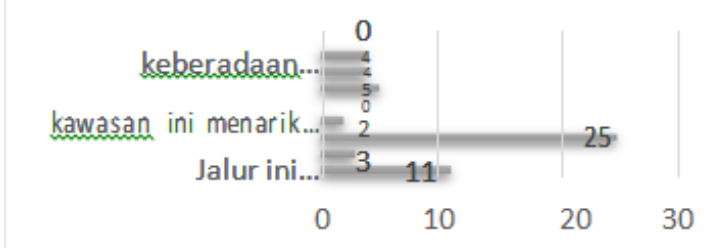

\section{Apa yang membuat Anda}

\section{memilih berjalan kaki di}

kawasan ini? (Anda dapat

memilih lebih dari satu)

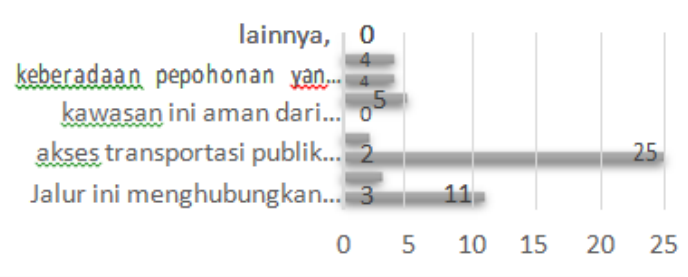

Malkhamah (1995) mengatakan bahwa pejalan kaki tidak dapat dipisahkan dari keberadaan manusia sesungguhnya. Oleh karena itu dimana pun tempat, baik di wilayah-wilayah pengembangan jasa, pemukiman, perdagangan maupun industri, fasilitas pejalan kaki tetap perlu disediakan. Konektivitas tersebut membuat suatu kawasan tersebut mudah di jangkau oleh masyarakat yang berada sekitar kawasan TOD maupun dari luar kawasan. Kurangnya fasilitas trotoar yang layak untuk pejalan kaki membuat masyarakat sekitar menjadi enggan jalan kaki.

Tahun 2007 hingga tahun 2014 total panjang trotoar tidak ada penambahan panjang sama sekali yaitu 540,3 ribu meter tidak sebanding dengan total panjang jalan pada tahun 2015 yang memiliki panjang sekitar 6.955.842 meter berarti panjang trotoar di Jakarta hanya sekitar 7,8\% dari total panjang jalan di Jakarta (BPS Jakarta, 2015). Lebih jauh, hal ini diperparah dengan jalur pejalan kaki menjadi neraka bagi pejalan kaki itu sendiri di karenakan data yang dihimpun dari Ditlantas Polda Metro Jaya pada tahun 2014, sebanyak 1 pejalan kaki meninggal dunia tiap 6 hari. Artinya nyawa pejalan kaki di negeri ini sangat terancam.

Aksesbilitas pejalan kaki pada kawasan TOD sangat perlu diperhatikan karena dapat berpengaruh terhadap minat masyarakat menggunakan transportasi umum untuk mobilisasi. Sebagaimana disebutkan dalam Peraturan Pemerintah RI No. 79 tahun 2013 tentang Pejalan Kaki dan 
Sepeda pasal 54 ayat (1) "jalan dilengkapi dengan fasilitas untuk sepeda, pejalan kaki, dan penyandang cacat sebagaimana dimaksudkan dalam pasal 26 huruf g”. Mengingat keterbatasan lahan untuk pembangunan kawasan TOD maka diperlukan penelitian lebih jauh tentang aksesbilitas pejalan kaki agar mudah, nyaman, dan aman ketika mau ke suatu tempat. Lebih jauh, untuk memenuhi kebutuhan aksesbilitas pejalan kaki dibutuhkan ketentuan atau standarisasi khusus untuk menentukan jalur pedestrian itu sendiri.

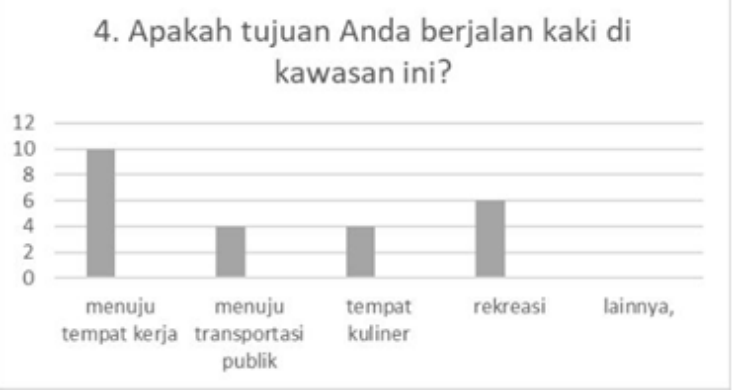

Hasil Pra-penelitian yang telah dilakukan berupa analisa kebutuhan menunjukkan bahwa kemudahan aksesbilitas menggunakan jalur pejalan kaki menuju stasiun maupun transportasi publik banyak dipilih itu artinya jalur pejalan kaki ini mempunyai peranan yang penting untuk pengguna krl maupun transportasi publik lainnya.

Dengan hal ini penulis ingin meneliti tentang Aksesbilitas Pejalan Kaki di Stasiun yang Terintegrasi Dengan Rencana Terhadap Kawasan Berkonsep TOD (Studi Kasus Kawasan Stasiun Tanjung Barat).

Berdasarkan latar belakang diatas dapat diidentifikasi permasalahannya sebagai berikut:

1) Aksesbilitas jalur pejalan kaki masih kurang sehingga minat masyarakat akan penggunaan transportasi pribadi lebih besar dibandingkan dengan kendaraan umum pada kawasan berkonsep TOD di sekitar Stasiun Tanjung Barat.

2) Kelayakan jalur pedestrian dalam segi keamanan maupun kenyaman masih sangat kurang terutama dari fasilitas penunjang untuk mencapai Stasiun Tanjung Barat di Kawasan TOD

Pembatasan masalah dalam penelitian ini adalah dari hanya segi kelayakan jalur pedestrian untuk aksesbilitasi pejalan kaki pada kawasan TOD dalam menjangkau fasilitas umum seperti: terminal, maupun stasiun yang akan berdampak pada tinggi minat masyarakat dalam menggunakan transportasi umum.

Berdasarkan pembatasan masalah diatas dapat dirumuskan penelitian ini sebagai berikut:

1) Bagaimana kelayakan aksesbilitas bagi pejalan kaki sebagai produk konsep TOD?

2) Apakah akan berdampak terhadap minat Masyarakatdenganmenggunakantranspo rtasi umum, jika kualitas aksesbilitas pejalan kaki ditingkatkan dalam segi keaman maupun kenyamanan?

Manfaat yang di dapat dari penelitian ini adalah :

1) Agar tingkat pelayanan fasilitas pejalan kaki menjadi baik serta bisa menampung jumlah pejalan kaki untuk kawasan TOD yang akan datang.

2) Agar menunjang jalur pejalan kaki yangaman, mudah serta keselamatan (keamanan).

Adapun tujuan penelitian adalah membuat permodelan jalur pedestrian yang sesuai dari segi kemanan maupun kenyamanan di kawasan sekitar Stasiun Tanjung Barat sebagai peningkatan minat masyarakat terhadap transportasi umum perkotaan.

\section{METODE}

Metode yang digunakan dalam penelitian ini adalah Penelitian dan Pengembangan (Research and Development) digunakannya metode ini karena melalui 
kajian sistematis mengenai proses perancangan, pengembangan, dan evaluasi yang bertujuan untuk mengembang produk yang sudah ada serta metode analisis trend linear untuk pengolahan data.

Teknik pengumpulan data pada penelitian ini menggunakan Teknik Observasi dan Wawancara Terstruktur. Observasi merupakan proses untuk memperoleh data dari tangan pertama dengan mengamati orang, atau proses kerja suatu produk di tempat pada saat dilakukan penelitian. peneliti memperoleh data pengamatan secara langsung. (Creswell, 2012). Wawancara digunakan sebagai teknik pengumpulan data apabila peneliti ingin melakukan pendahuluan untuk menemukan permasalahan dan potensi yang harus diteliti, dan juga apabila peneliti ingin mengetahui pendapat, keinginan dan hal-hal lain dari responden yang lebih mendalam (Sugiyono, 2015: 210).

Penelitian ini menggunakan Teknik Analisis Data Deksriptif kualitatif. Menurut: Statistik deskriptif adalah statistik yang digunakan untuk menganalisis data dengan cara mendeskripsikan atau menggambarkan data yang telah terkumpul sebagaimana adanya tanpa bermaksud membuat kesimpulan yang berlaku untuk umum atau generalisasi (Sugiyono, 2012: 147). Teknik analisis data deskriptif kualitatif digunakan untuk mengolah data hasil evaluasi oleh ahli materi, ahli pengembangan instrumen dan ahli perencanaan tata kota. Teknik analisis data tersebut dilakukan degan mengelompokan informasi-informasi dari data kualitatif yang berupa masukan, tanggapan kritik dan saran perbaikan yang dituliskan pada angket. Hasil analisis tersebut kemudian digunakan untuk merevisi produk Permodelan daerah sekitar Stasiun Tanjung Barat berkonsep TOD.

\section{HASIL DAN PEMBAHASAN}

Hasil pehitungan Level Of Service (LOS) karakteristik pejalan kaki di Stasiun Tanjung Barat sebagai berikut: Di Jl. Tanjung Barat Raya, pada hari kerja di jam berangkat yaitu $8-10$ Pagi dan jam pulang kerja yaitu $4-6$ sore. Untuk data Arus didapat 4,88 pedestrian $/ \mathrm{m} / \mathrm{min}$. untuk kecepatan pejalan kaki didapat 16,73 $\mathrm{m} / \mathrm{min}$. Untuk Kepadatan didapat 0,264 pedestrian/m2. Ruang Pejalan Kaki 4,056 m2/pedestrian. Di Jl. Lenteng Agung Raya, pada hari kerja di jam berangkat yaitu 8 10 Pagi dan jam pulang kerja yaitu $4-6$ Sore. Untuk data Arus didapat 11,23 pedestrian $/ \mathrm{min} / \mathrm{m}$. untuk kecepatan pejalan kaki didapat $16,78 \mathrm{~m} / \mathrm{min}$. Untuk Kepadatan didapat 0,67 pedestrian $/ \mathrm{m} 2$. Ruang Pejalan Kaki 1,485 m2/pedestrian.

Berdasarkan data besarnya arus, kepadatan, kecepatan dan nilai ruang pejalan kaki waktu interval 10 menit, maka tingkat pelayanan pejalan kaki di Stasiun Tanjung Barat ada sebagai berikut : Untuk jalur pejalan kaki di jl. Tanjung Barat Raya termasuk dalam tingkat pelayanan "B", sedangkan. Untuk jalur pejalan kaki di jl. Lenteng Agung Raya termasuk dalam tingkat pelayanan "C". Sehingga tingkat pelayanan pejalan kaki di sekitar Stasiun Tanjung Barat dalam kategori cukup atau memenuhi standar Highway Capacity Manual (HCM) 2000.

Hasil perhitungan Trend Linear (prediksi 5 tahun mendatang) pejalan kaki di Stasiun Tanjung Barat berikut :Pada tahun 2018 kenaikan jumlah penumpang diperkirakan mencapai 10.523 .966 penumpang (LOS B). Pada tahun 2019 kenaikan jumlah penumpang diperkirakan mencapai 11.147.392,1 penumpang (LOS B). Pada tahun 2020 kenaikan jumlah penumpang diperkirakan mencapai 11.761.817,6 penumpang (LOS B). Pada tahun 2021 kenaikan jumlah penumpang diperkirakan mencapai 12.376.234,1 penumpang (LOS B). Pada tahun 2022 kenaikan jumlah penumpang diperkirakan mencapai 12.990.668,6 penumpang (LOS B) 


\section{KESIMPULAN}

Berdasarkan dari hasil analisis dan pembahasan maka dapat diambil kesimpulan sebagai berikut :

1) Hasil perhitungan data arus, kecepatan rata-rata, kepadatan, serta ruang gerak pejalan kaki menunjukkan bahwa tingkat kualitas pelayanan pejalan kaki pada jl. Tanjung Barat Raya dan jl. Lenteng Agung Raya berturut-turut kategori "B" dan "C" artinya perlu ditingkatkan lagi dari sisi fasilitas penunjang agar masyarakat aman dan nyaman ketika menggunakan jalur pejalan kaki dan model rencana rancangan yang penulis buat menjadi referensi untuk contoh jalur pejalan kaki yang ideal.

2) Hasil Analisa Kebutuhan yang telah dilakukan menunjukkan bahwa pejalan kaki yang menggunakan jalur pejalan kaki menginginkan adanya perbaikan dari segi keamanan maupun kenyamanan sebab kualitas jalur pejalan kaki eksisting sangat tidak terjamin keamanan dan kenyamanannya. Salah contoh yang terlihat adalah kurang idealnya jalur pejalan kaki yang lebarnya kurangnya dari 2 (dua) meter membuat interaksi ketika jam berangkat kerja maupun jam pulang kerja terjadi kepadatan yang cukup tinggi. Selain itu, tidak adanya pagar penghalang antara jalur pejalan kaki dengan jalan raya membuat hampir sering kali hampir terserempet kendaraan yang lalu-lalang.

\section{REFERENSI}

Creswell, J.W. (2012) RESEARCH DESIGN Pendekatan Kualitatif, Kuantitatif, dan Mixed. Yogyakarta: Pustaka Pelajar
BPS. (2015). Panjang Trotoar di Jakarta 200-2014. Jakarta: BPS.

HCM. (2000). Highway Capacity Manual. Washington DC: Transportation Research Board National Research Council.

ITDP (2017, Juli 4). TOD Standard. Retrieved from http://www.itdp indonesia.org/:http://www.itdpindonesia.org/featured-pub-4/todstandard-3/

Malkhamah. (1995).Manajemen

Lalulintas Kota Secara Terpadu, Untuk Pelestarian Lingkungan dan Keselamatan Lalu lintas. Yogyakarta: Biro Penerbit.

$\begin{array}{cl}\text { Menteri } \quad \text { Pekerjaan } & \text { Umum dan } \\ \text { Perumahan Rakyat } & \text { (2014). } \\ \text { PEDOMAN } & \end{array}$

PERENCANAAN, PENYEDIAAN, DAN PEMANFAATAN PRASARANA DAN SARANA JARINGAN PEJALAN KAKI DIKAWASAN PERKOTAAN No. 3 Tahun 2014. Jakarta.

Peraturan Pemerintah RI. (2013). JARINGAN LALU LINTAS DAN ANGKUTAN JALAN NO. 79. Jakarta

Sugiyono. (2015).Metode Penelitian \& Pengemgembangan (Research and Development). Jakarta : ALFABETA

Tamin. (2008). Perencanaan, Pemodelan, dan Rekayasa Transportasi: Teori, Contoh Soal dan Aplikasi. Bandung: Penerbit ITB. 